\title{
Synthesis of prostaglandin $\mathrm{E}_{2}$, thromboxane $\mathrm{B}_{2}$ and prostaglandin catabolism in gastritis and gastric ulcer
}

\author{
C J HAWKEY \\ (WITH THE TECHNICAL ASSISTANCE OF N K BHASKAR AND B FILIPOWICZ)
}

From the Department of Therapeutics, University Hospital, Nottingham

SUMMARY Because endogenous prostaglandins may protect the gastric mucosa a study was conducted to determine factors influencing (a) the synthesis of immunoreactive prostaglandin (iPG) $E_{2}$ and thromboxane (iTx) $B_{2}$ as measured by radioimmunoassay and (b) prostaglandin catabolism measured radiometrically, in human gastric mucosa. Gastric mucosa was obtained at endoscopy. Synthesis of $\mathrm{iPE}_{2}$ and $\mathrm{iTxB}_{2}$ was inhibited in vitro by indomethacin; $\mathrm{iTxB}_{2}$ synthesis was also selectively inhibited by the thromboxane synthesis inhibitor dazmegrel. Prostaglandin catabolism was inhibited by carbenoxolone. Multivariate analysis showed that synthesis of iPGE 2 from endogenous precursor during homogenisation was decreased in patients on non-steroidal anti-inflammatory drugs. Mucosal inflammation was associated with significantly increased synthesis of $\mathrm{iPGE}_{2}$ and decreased prostaglandin catabolism. There were no differences between the mucosa of patients with or without gastric ulcers, nor between the ulcer rim and mucosa $5 \mathrm{~cm}$ away. Age, sex, smoking history, and ingestion of antisecretory drugs appeared to exert no influence. In this study gastritis was the major influence on prostaglandin synthesis. It seems unlikely that prostaglandin deficiency is a strong predisposing factor for gastric ulceration.

Reports suggesting gastric mucosal protection by endogenous prostaglandin synthesis ${ }^{1-3}$ raise the possibility that this process might be defective in patients who develop gastric ulcers. Previous evidence on this point has been conflicting. Some studies have found reduced prostaglandin synthesis in gastric ulcer patients, ${ }^{45}$ even in the presence of gastritis: this would be surprising because other inflammatory lesions lead to enhanced prostaglandin synthesis. Another study reported increased prostaglandin synthesis in patients with gastric ulcers $^{\circ}$ and attributed this to the associated gastritis: however, even where this occurs it remains possible that prostaglandin synthesis could be deficient in relation to the prevailing levels of mucosal inflammation.

Factors other than reduced prostaglandin synthesis might render the mucosa liable to ulcerate. These could include an absolute or relative enhance-

Address for correspondence: Dr ( J Hawkey. Department of Therapeutics. University Hospital. Nottingham NG7 $2 \mathrm{UH}$.

Received for publication 22 April 1986 ment of thromboxane synthesis as thromboxane synthesis is associated with gastric ulceration in rats and inhibitors of thromboxane synthesis appear to be protective. ${ }^{7-11}$ Alternatively reduced levels of protective prostaglandins might result from increased prostaglandin catabolism. 121.3

In this study synthesis of immunoreactive prostaglandin (iPG) $\mathrm{E}_{2}$ and of thromboxane $(\mathrm{iTx}) \mathrm{B}_{2}$, and prostaglandin catabolism in human gastric mucosa have been investigated with reference both to histological appearances and to the presence or absence of gastric ulceration. The relationship of age, sex or smoking or ingestion of non-steroidal anti-inflammatory drugs (NSAIDS) or antisecretory drugs to these parameters has also been investigated in view of the known influence of these factors on the incidence or natural history of gastric ulceration.

\section{Methods}

PATIENTS

The following radiolabelled compounds were used: $\left(\mathrm{H}_{3}\right) \mathrm{PGE}_{2}, 160 \mathrm{Ci} / \mathrm{mmol}$ (Amersham International); 
$\left(\mathrm{H}_{3}\right) \mathrm{TxB}_{2}, 139 \cdot 3 \mathrm{Ci} / \mathrm{mmol}$ (New England Nuclear) and $\left(9 \mathrm{H}_{3}\right) \mathrm{PGF}_{2}, 13.7 \mathrm{Ci} / \mathrm{mmol}$ (Amersham International). The following compounds were gifts: indomethacin (Merck Sharp \& Dohme), dazmegrel (Pfizer UK), carbenoxolone (Biorex Laboratories). $\mathrm{TxB}_{2}$ antiserum was kindly donated by Dr Lawrence Levine. $\mathrm{PGE}_{2}$ antiserum was bought from the Institut Pasteur. Other chemicals were obtained from standard laboratory suppliers.

Patients undergoing upper gastrointestinal endoscopy with an Olympus $T$ endoscope were studied. Where there was a possibility that mucosa might be taken for research patients were asked to give written informed consent before the endoscopy. The study was approved by the South Nottingham Ethical Committee.

In studies used to develop and validate the incubation conditions and radioimmunoassays and to assess reproducibility with repeated study, both normal subjects and patients with a variety of gastroduodenal conditions were studied. During the main study 27 patients with gastric ulcers and 43 control patients were studied. As gastritis was one of the factors which the study was designed to investigate, endoscopic or histological evidence of inflammation was not an exclusion criterion. In all other respects, the control patients had normal endoscopic findings. The characteristics of the patients studied are detailed in Table 1.

\section{HISTOLOGY}

Four to five mucosal biopsy specimens were taken from the lesser curve between 45 and $50 \mathrm{~cm}$ from the incisor teeth and used immediately. A small piece from two of the specimens, or a separate biopsy specimen from the same area was examined histologically (without knowledge of the biochemical results) and graded as uninflamed (normal or only

Table 1 Characteristics of the patients studied

\begin{tabular}{lcc}
\hline & Control & GU patients \\
Total & & \\
Men & 43 & 27 \\
Smokers & 29 & 13 \\
Antisecretory drugs & 16 & 17 \\
NSAIDS & 9 & 17 \\
Age <30 years & 5 & 4 \\
$\quad 3(1-50$ & 7 & - \\
$\quad 5(1-65$ & 11 & - \\
$\quad 65-75$ & 9 & 11 \\
$\quad 75+$ & 11 & 14 \\
& 4 & 2 \\
\hline
\end{tabular}

*Patients on regular NSAID's, last dose in each case approximately 12 hours before endoscopy: individual drugs as follows:indomethacin: five, aspirin: two, naproxen: one. flurbuprofen: one. slight increase in inflammatory cell infiltrate) or inflamed (moderate or marked increase in inflammatory cell infiltrate) using standard histological criteria of inflammation. ${ }^{1+}$ No attempt was made to differentiate between inflammation caused mainly by neutrophils and inflammation caused mainly by lymphocytes. As mucosal atrophy and mucosal inflammation were frequently associated no attempt was made to assess them independently.

\section{HOMOGENATES AND INCUBATIONS}

The rest of the biopsy specimens were homogenised immediately on ice in Tris $\mathrm{HCl}(0 \cdot 05 \mathrm{M}, \mathrm{pH} 7 \cdot 4$ (20) $\mathrm{mg}$ wet weight $/ \mathrm{ml}$, final proportions) for 15 seconds using an Ultraturax homogenizer.

SYNTHESIS FROM ENDOGENOUS STORES

(ENDOGENOUS $\mathrm{PPGE}_{2} \wedge \mathrm{ND}$ ) $\mathrm{iT}_{\mathrm{T}} \mathrm{B}_{2}$ )

Ten milligram aliquots in $0.5 \mathrm{ml}$ (final proportions) of the homogenate were extracted immediately into chloroform, ${ }^{15}$ for the determination of prostanoids synthesised from endogenous stores (henceforth designated Endogenous $\mathrm{iPGE}_{2}$ or $\mathrm{iTxB}_{2}$ ).

\section{INHIBITOR EXPERIMENTS}

Some samples were pre-incubated in Tris $\mathrm{HCl}$ containing either indomethacin $50 \mu \mathrm{g} / \mathrm{ml}\left(4 \times 10^{-4} \mathrm{M}\right)$ for 15 minutes before being homogenised in fresh Tris $\mathrm{HCl}$ also containing indomethacin $50 \mu \mathrm{g} / \mathrm{ml}$ $\left(4 \times 10^{-4} \mathrm{M}\right)$. These samples were extracted in the usual way and results compared with those obtained from biopsies from the same patient but not exposed to indomethacin.

SYNTHESIS AFTER INCUBATION WITH ARACHIDONIC ACID (TOTAL IPGE 2 SYNTHESIS)

Other aliquots (10 mg, $0.5 \mathrm{ml}$, final proportions) were incubated with arachidonic acid $2 \mu \mathrm{g}$ for 30 minutes at $37^{\circ} \mathrm{C}$ in a rocking water bath before extraction into chloroform. ${ }^{15}$ Because this procedure results in synthesis of prostanoids from both endogenous and exogenous arachidonic acid it is designated Total $\mathrm{iPGE}_{2}$ synthesis.

\section{INHIBITOR EXPERIMENTS}

In some experiments aliquots of homogenates were incubated with or without indomethacin $1 \mu \mathrm{g} / \mathrm{ml}$ $\left(2.8 \times 10^{-6} \mathrm{M}\right)$ or dazmegrel $0.3 \mu \mathrm{g} / \mathrm{ml}\left(10^{-6} \mathrm{M}\right)$. The effect of the inhibitor was calculated after allowance for synthesis during homogenisation.

\section{RADIOIMMUNOASSAYS}

After extraction into chloroform, samples were

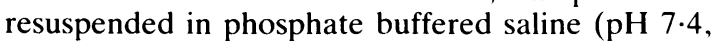
$0 \cdot 15 \mathrm{M})$, and stored at $-50^{\circ} \mathrm{C}$ for radioimmunoassay, usually within one month (maximum three 
months). $\mathrm{iTxB}_{2}$ was measured by radioimmunoassay using anti-serum kindly donated by Dr Lawrence Levine. For thromboxane assays standard $\mathrm{TxB}_{2}$, $\mathrm{TxB}_{2}$ anti-serum and $\left[\mathrm{H}^{3}\right] \mathrm{TxB}_{2}$ tracer (Amersham) were dissolved and samples were diluted in Tris saline $\mathrm{pH} 7 \cdot 4,0.15 \mathrm{M}$ with $1 \%$ gelatin. $\mathrm{iPGE}_{2}$ was measured by radioimmunoassay as previously described. ${ }^{1617}$

\section{CATABOLISM}

Aliquots of homogenate $(10 \mathrm{mg} 0.5 \mathrm{ml}$, final proportions) were also incubated with $\left(9 \beta-\mathrm{H}^{3}\right) \mathrm{PGF}_{2 \alpha}$ $(1 \mathrm{mg}, 0 \cdot 1 \mu \mathrm{Ci}$ ) and NAD $1 \mathrm{~mm}$ for five minutes at $37^{\circ} \mathrm{C}$. They were extracted into chloroform at $\mathrm{pH}$ 3.5 and re-suspended in $75 \mu \mathrm{l}$; chloroform:ethanol (1:1). PGF $_{2 \varkappa}$ and its metabolites were separated by thin layer chromatography using Watman LK6D silica gel chromatography plates and ethyl acetate: acetone:acetic acid $(9(): 10: 1)$ as solvent. Regions corresponding to authentic $\mathrm{PGF}_{2 \alpha}, 15$ keto $\mathrm{PGF}_{2 \alpha}$, $13 \cdot 14$ dihydro $\mathrm{PGF}_{2 \alpha}$ and $13 \cdot 14$ dihydro 15 keto $\mathrm{PGF}_{2 \alpha}$ were scraped and added direct to LKB Optiphase scintillant for quantitation by liquid scintillation counting. Radioactivity cochromatographing with metabolites was expressed as a per cent of total radioactivity scraped. A similar value derived using boiled mucosa from the same patient was then deducted to obtain values for the percentage of enzymatic catabolism in samples.

\section{INHIBITOR EXPERIMENTS}

In some experiments, aliquots of the homogenate were preincubated on ice for 15 minutes with carbenoxolone $57 \mu \mathrm{g} / \mathrm{ml}\left(10^{-4} \mathrm{M}\right)$ or $5.7 \mu \mathrm{g} / \mathrm{ml}$ $\left.10^{-5} \mathrm{M}\right)$ and then incubated with $\left(9 \beta-\mathrm{H}_{3}\right) \mathrm{PGF}_{2 \alpha}$ $(1 \mu \mathrm{g}, 25 \mathrm{nCi})$ and NAD $1 \mathrm{~mm}$ for 15 minutes at $37^{\circ} \mathrm{C}$.

\section{STATISTICAI. METHODS}

The catabolism data approximated to a normal distribution but all synthesis data were transformed logarithmically to obtain a normal distribution for analysis. The influence of gastritis, gastric ulceration, age, sex, smoking, drug ingestion, and study number (to allow for any changes in experimental technique with time) upon prostaglandin synthesis and catabolism were investigated by multivariate analysis (Statistical Package for Social Sciences Programme). Paired data were evaluated using the paired $t$ test.

\section{Results}

VALIDITY OF RADIOIMMUNOASSAYS

(i) $i P G E_{2}$

In these experiments assay of samples at two-fold dilutions gave similar results (value at higher dilution $99+3 \%$, SEM, of value at lower dilution, $n=6$ ). Authentic $\mathrm{PGE}_{2}$ added to samples before extraction was assayed as $103 \pm 4 \% \quad(n=48)$ of that added. Prostaglandin $E_{2}$ re-assayed in samples after one to three months of storage was $105 \pm 9 \%(n=101)$ of initial value. The $\mathrm{PGE}_{2}$ antiserum showed selective reactivity with material cochromatographing with authentic $\mathrm{PGE}_{2}$.

\section{(ii) $i T x B_{2}$}

Under the assay conditions used, the cross reactivity of the $\mathrm{TxB}_{2}$ antiserum with other prostanoids (based on concentrations required to produce $50 \%$ displacement of $\left.\left(\mathrm{H}_{3}\right) \mathrm{TxB}_{2}\right)$ was as follows: $\mathrm{PGD}_{2}$ : $1 \cdot 2 \%$ PGF $_{1 \alpha}: 0 \cdot 12 \%$; PGE $2: 0 \cdot 1 \%$ PGF $_{2 \alpha}: 0 \cdot 01 \%$; arachidonic acid, $\mathrm{PGA}_{2}, 6$ keto $\mathrm{PGF}_{1 \alpha}$ and $13 \cdot 14$ dihydro 15 keto $\mathrm{PGE}_{2}$ : all $<0 \cdot 001 \%$. Assay of samples at two dilutions gave similar results (value at higher dilution $=105+5 \%$ of value at lower dilution, $\mathrm{n}=15)$. Authentic $\mathrm{TxB}_{2}$ added to samples before or after extraction was assayed as $90+9 \%$ $(n=20)$ of that added. $\mathrm{TxB}_{2}$ re-assayed after one to three months of storage was $109+1 \% \quad(n=53)$ of initial value. $\mathrm{TxB}_{2}$ anti-serum showed selective reactivity with material cochromatographing with authentic $\mathrm{TxB}_{2}$.

QUALITY CONTROL

Preliminary experiments showed that $\mathrm{iPGE}_{2}$ and $\mathrm{iTxB}_{2}$ (measured by radioimmunoassay) were recovered to a similar extent $\left(69 \pm 1 \%\right.$ for $\mathrm{PGE}_{2}$ and $69 \pm 2 \%$ for $\left.\mathrm{TxB}_{2}\right) \quad(\mathrm{n}=3$ each $)$. In subsequent experiments $\left(\mathrm{H}_{3}\right) \mathrm{PGE}_{2}$ was used to measure recovery: mean recoveries were $72 \%$. Three external standards of $\mathrm{PGE}_{2}$ or of $\mathrm{TxB}_{2}$ were included in each radioimmunoassay and two samples previously assayed satisfactorily were re-assayed to ensure accuracy and consistency from one assay to another.

HOMOGENATES

EFFECTS OF INHIBITORS IN VITRO

(a) Immediate extraction (Endogenous ${ }^{P} P E_{2}$ and $T x B_{2}$ )

Synthesis of $\mathrm{iPGE}_{2}$ was inhibited by $60 \pm 8 \%(n=8)$ if homogenisation was carried out in the presence of indomethacin, $50 \mu \mathrm{g} / \mathrm{ml}\left(1.4 \times 10^{-4} \mathrm{M}\right)$. Under these conditions synthesis of $\mathrm{iTxB}_{2}$ was reduced by $68 \pm 6 \%(n=8)$.

\section{(b) Incubated synthesis}

Synthesis of $\mathrm{iPGE}_{2}$ was inhibited by $72 \pm 9 \%$ and of $\mathrm{iTxB}_{2}$ by $63 \pm 15 \%(\mathrm{n}=4)$ by indomethacin $1 \mu \mathrm{g} / \mathrm{ml}$ $\left(2 \cdot 8 \times 10^{-6} \mathrm{M}\right)$. The thromboxane synthesis inhibitor dazmegrel $0.3 \mu \mathrm{g} / \mathrm{ml}\left(10^{-6} \mathrm{M}\right)$ inhibited $\mathrm{iTxB}_{2}$ synthesis by $44 \pm 21 \%$; synthesis of $\mathrm{iPGE}_{2}$ was $243 \pm 69 \%$ control $(n=4)$. 

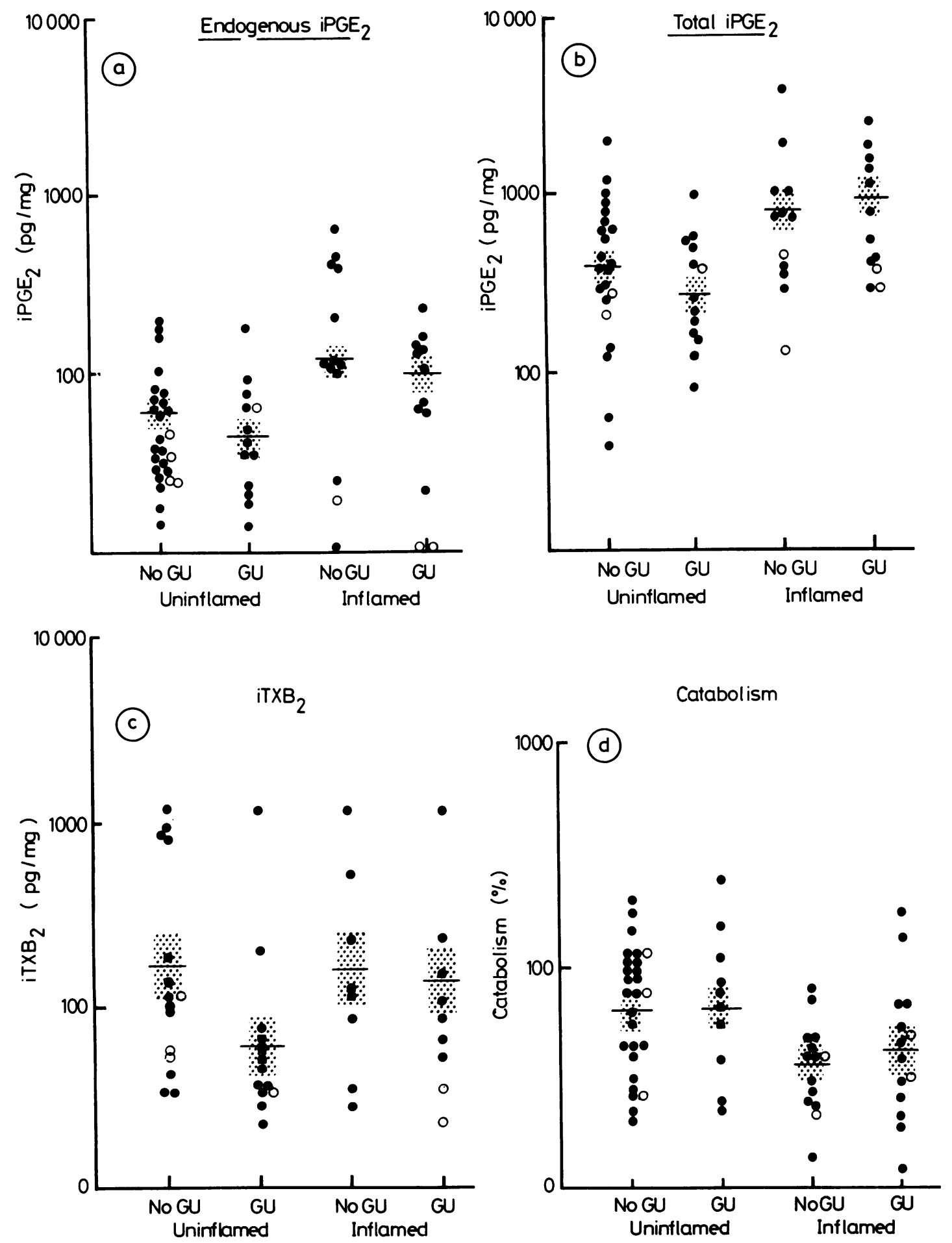
(c) Catabolism

Carbenoxolone inhibited prostaglandin catabolism by $29 \pm 9 \%$ at $10^{-5} \mathrm{M}(\mathrm{n}=8)$ and by $79 \pm 5 \%$ at $\left.10^{-4} \mathrm{M}\right)(\mathrm{n}=6)$.

\section{REPRODUCIBILITY}

Eighteen patients were studied on two occasions after receiving in the intervening period, misoprostol $(n=7)$, trimoprostil $(n=4)$, placebo $(n=4)$, cimetidine $(n=2)$ and ranitidine $(n=1)$. Two way analysis of variance showed that patients differed significantly from each other but that there was no significant change after the period of treatment. Based on the residual variance, the coefficients of variation for repeated study were: for endogenous $\mathrm{iPGE}_{2}: 14 \%$; for total $\mathrm{iPGE}_{2}: 10 \%$; for $\mathrm{iTxB}_{2}: 17 \%$ (all logarithmically transformed data) and for prostaglandin catabolism (untransformed data): $33 \%$.

\section{INFLUENCE OF PATIENT CHARACTERISTICS ON}

SYNTHESIS AND CATABOLISM

Table 2 shows all factors having a statistically significant or near significant influence on the dependent variables studied. Where patients were studied more than once the first data only were

Table 2 Factors influencing the synthesis and catabolism of prostanoids in human gastric mucosa

\begin{tabular}{|c|c|c|c|c|c|}
\hline $\begin{array}{c}\text { Dependent } \\
\text { variable }\end{array}$ & $n$ & Influence & $R$ & $F$ & $p$ \\
\hline $\begin{array}{l}\text { Ln(Endo- } \\
\text { genous } \\
\left.\text { PGE }_{2}\right)\end{array}$ & 64 & $\begin{array}{l}\text { NSAIDS } \\
\text { Inflammation } \\
\mathrm{GU}\end{array}$ & $\begin{array}{r}-0.31 \\
0.28 \\
-(1) .15\end{array}$ & $\begin{array}{l}8 \cdot 30 \\
8 \cdot 39 \\
3 \cdot 73^{*}\end{array}$ & $\begin{array}{l}<() \cdot() 1 \\
<() \cdot() 1 \\
<() \cdot 1^{*}\end{array}$ \\
\hline $\begin{array}{r}\text { Ln(Total } \\
\left.\quad P E_{2}\right)\end{array}$ & 60 & $\begin{array}{l}\text { Inflammation } \\
\text { Study number }\end{array}$ & $\begin{array}{l}(1) .37 \\
(1) \cdot 32\end{array}$ & $\begin{array}{l}9 \cdot 81 \\
7 \cdot(015\end{array}$ & $\begin{array}{l}<() \cdot() 1 \\
<() \cdot(0.5\end{array}$ \\
\hline $\operatorname{Ln}\left(\mathrm{TXB}_{2}\right)$ & 45 & $\begin{array}{l}\text { Study number } \\
\text { GU }\end{array}$ & $\begin{array}{r}0.42 \\
-0.28\end{array}$ & $\begin{array}{l}8.99 \\
3.85 \div\end{array}$ & $\begin{array}{l}<0 \cdot() 1 \\
<() \cdot 1 \div\end{array}$ \\
\hline Catabolism & 70 & $\begin{array}{l}\text { Study number } \\
\text { Inflammation }\end{array}$ & $\begin{array}{r}(1.32 \\
-0.23\end{array}$ & $\begin{array}{l}8 \cdot 68 \\
5 \cdot 10\end{array}$ & $\begin{array}{l}<() \cdot(0) 1 \\
<() \cdot(05\end{array}$ \\
\hline
\end{tabular}

$\mathrm{Ln}=$ natural logarithm

$\mathrm{R}=$ simple correlation coefficient $\mathrm{F}=$ variance ratio

"Critical F values - $4 \cdot()()(p<0 \cdot(1) 5), 2 \cdot 80(p<0) \cdot 10)$

+ Critical F values - 4.(1)8 $(\mathrm{p}<(1) \cdot(05), 2 \cdot 85(\mathrm{p}<0) \cdot 10)$

The Table only shows those variables where a $p$ value less than $0 \cdot 1$ was obtained. used. Inflammation was a major influence and was associated with increased synthesis of $\mathrm{iPGE}_{2}$ (both endogenous and total) as well as reduced prostaglandin catabolism (Fig. 1). Patients taking nonsteroidal anti-inflammatory drugs showed reduced synthesis of prostanoids (Fig. 1): this was statistically significant for endogenous $\mathrm{PPGE}_{2}$. The study number was a significant influence on prostaglandin catabolism, Total $\mathrm{iPGE}_{2}$ and $\mathrm{iTxB}_{2}$ : values of all three increased gradually as the study progressed. Finally there were trends towards lower levels of ${ }_{2} \mathrm{PGE}_{2}$ and of $\mathrm{iTxB}_{2}$ in patients with gastric ulceration but these did not reach conventional levels of significance. No other factor showed statistically significant influence.

\section{UI.CER RIM VERSUS INTACT MUCOSA}

In 18 patients mucosa was obtained from the rim of the gastric ulcer: ulcerated slough and fibrous tissue in the base were avoided. Synthesis of $\mathrm{iPGE}_{2}, \mathrm{iTxB}_{2}$ and prostaglandin catabolism in the ulcer rim was compared with that from mucosa on the lesser curve at least $5 \mathrm{~cm}$ away. As seen in Figure 2 there is little difference between the ulcer rim and the intact mucosa.

PAIRED DATA, GASTRIC ULCER VERSUS

NON-GASTRIC ULCER PATIENTS

Twelve pairs of patients could be identified, matched for levels of inflammation, drug intake, sex, age (to within seven years) and study date (to within three months), differing only with regard to the presence or absence of gastric ulceration. There were no significant differences in the synthesis of $\mathrm{PPGE}_{2}$, $\mathrm{iTxB}_{2}$ or of prostaglandin catabolism (Fig. 3).

\section{Discussion}

The main conclusions from these data are that ${ }^{2} \mathrm{PGE}_{2}$ synthesis as measured in the study is increased and that prostaglandin catabolism is reduced in the presence of gastritis. After allowing for the influence of coexisting inflammation, however, there were no significant differences between gastric mucosa from patients with or without gastric ulceration.

Radioimmunoassays were used as the bases of measurement for synthesis. In these studies as with

Fig. 1 Synthesis and catabolism of prostanoids in gastric mucosa: effect of gastritis and gastric ulceration. (a) iPGE, synthesised from endogenous substrate (Endogenous iP $\left(G E_{2}\right)$ in $\mathrm{pg} / \mathrm{mg}$ wet weight. (b) Total iP( $; E_{2}$ (after incubation with exogenous arachidonic acid) in $\mathrm{pg} / \mathrm{mg}$ wet weight. (c) $i T x B_{2}$ (synthesised from endogenous stores) in $\mathrm{pg} / \mathrm{mg} n \mathrm{net}$ weight. (d) Catabolism of (9/) $H^{3} P\left(G F_{2 a}: \%\right.$ conversion to metabolites calculated as described in text. $\bigcirc$ represent patients taking non-steroidal anti-inflammatory drugs. - all other patients. — show means. Stippled areas show SEM's. 

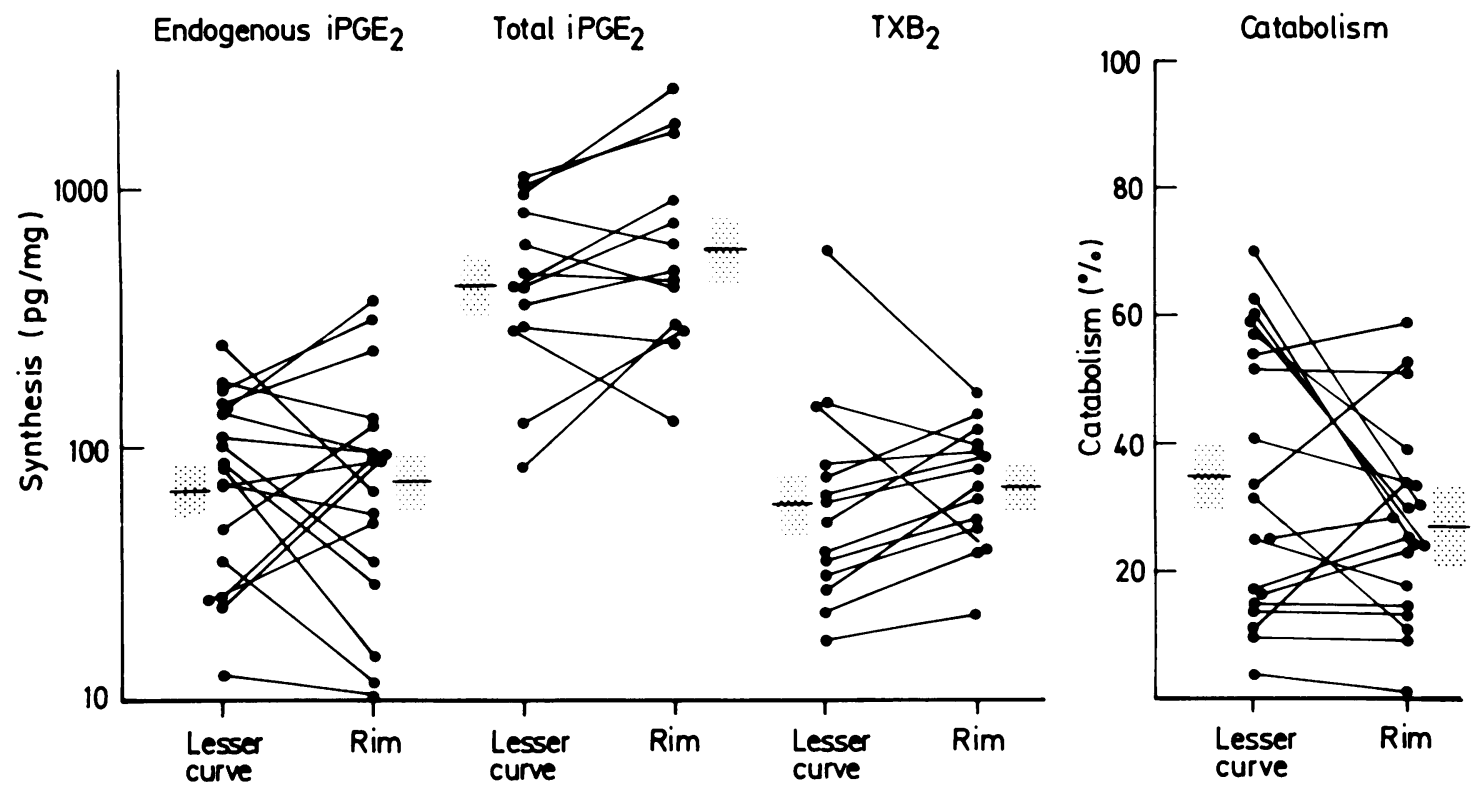

Fig. 2 Synthesis and catabolism of prostanoids in gastric ulcer patients: comparison of mucosa away from the ulcer (lesser curve) and from the ulcer rim. Results from lesser curve and from the ulcer rim are joined for each individual patient - show means. Stippled areas show SEM's.

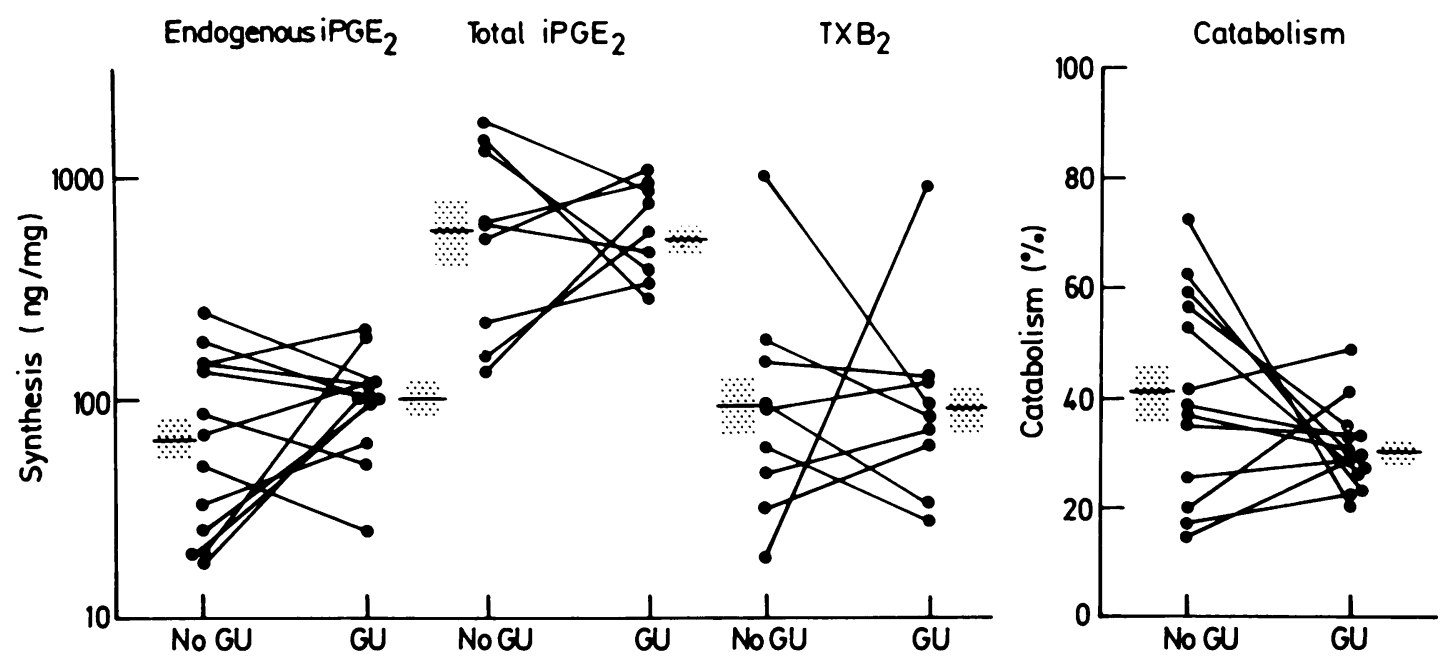

Fig. 3 Synthesis and catabolism of prostanoids in gastric mucosa: comparison of gastric ulcer patients with matched controls. Each pair of connected points shows results from an individual gastric ulcer patient joined to those' obtained from the matched control. - show means. Stipped areas show SEM's.

others using radioimmunoassay it is possible that crossreacting substances were at least in part measured. This is acknowledged by use of the terms immunoreactive $\mathrm{PGE}_{2}$ or $\mathrm{TxB}_{2}$ although it seems unlikely that another sibstance would cross react with the antiserum, cochromograph with the prosta- noid and that its synthesis would be inhibited in an appropriate way by indomethacin or dazmegrel. The rather modest reduction $(60-70 \%)$ in immunoreactive prostanoids synthesised during homogenisation achieved by high concentration of indomethacin could be taken as evidence that substances other 
than cyclo-oxygenase products were measured. Greater inhibition was seen, however, with lower concentration of indomethacin in the incubated homogenates and other explanations for the results obtained during homogenisation are more likely: there may have been incomplete diffusion of indomethacin and consequently only partial cyclooxygenase inhibition so that some synthesis occurred during homogenisation. The present results are also consistent with earlier data and the suggestion accompanying them that in gastric mucosa there may in fact be a small resting content of prostanoids ${ }^{18}$ though methodological difficulties make it impossible to resolve this point with certainty.

Prostaglandin catabolism was measured radiometrically. Prostaglandin $F_{2 u}$ was used as substrate because of its resistance to non-enzymatic catabolism. The assay is of enzyme activity in a defined system and should not be taken to imply that $\mathrm{PGF}_{2 \alpha}$ is normally the main prostaglandin catabolised by this pathway. Inhibition of prostaglandin catabolism by carbenoxolone has been reported before. In the present study different methodology has been used to confirm that carbenoxolone inhibits prostaglandin catabolism with a potency similar to that previously reported. ${ }^{19}$

The enhanced synthesis of $\mathrm{PGE}_{2}$ with gastritis presumably reflects the infiltration of the mucosa by inflammatory cells: human neutrophils and macrophages both have the capacity to synthesise $\mathrm{PGE}_{2}{ }^{21}$ These differences between inflamed and uninflamed mucosa are similar to those shown by Schlegel et al. ${ }^{\circ}$ Doubt has been expressed as to the validity of these earlier data as the amounts of $\mathrm{PGE}_{2}$ synthesised appeared to be very high. In the present study the quantities measured were much lower but the pattern of results was the same. The reduction in prostaglandin catabolism in inflamed tissue has not been shown before. Two main explanations are possible. One is that a primary defect in prostaglandin catabolism leads to increased mucosal levels of pro-inflammatory prostaglandins and makes the mucosa more liable to become inflamed. An alternative explanation is that the reduced prostaglandin catabolism is a consequence rather than a cause of the inflammation: gastric mucosa has an exceptionally high capacity for prostaglandin catabolism $^{12} 13$ which might fall because of the mucosal atrophy which accompanies the inflammation in gastritis. ${ }^{1+}$

Whatever the mechanism, increased synthesis and reduced catabolism of prostaglandins would both lead to increased tissue levels in gastritis. As with ulcerative colitis, the significance of increased prostaglandin synthesis in gastritis must be viewed in the context of the known properties of prostaglandins. ${ }^{21}$
In both situations, it is difficult to ascribe a central role to prostaglandins because they do not have properties which make them likely to cause recruitment of inflammatory cells or to lead to mucosal atrophy. Vasodilator prostaglandins may, however, give rise to mucosal redness sometimes seen in association with acute superficial gastritis. The mediators responsible for the recruitment of inflammatory cells in gastritis however remain unidentified. Obvious candidates which require investigation are leukotriene $\mathrm{B}_{4}$ and other related chemotactic lipoxygenase products.

Although there were large differences between patients the data show reasonable within patient consistency on repeated study, despite intervening treatment with a variety of therapeutic agents. The purpose of the reproducibility study was to validate the methodology rather than investigate the effects of individual drugs and the numbers are too small to exclude the possibility that some of the treatments influenced subsequent prostanoid synthesis. Antisecretory drug treatment, however, was not a significant influence on any of the variable investigated in the main study in contrast with the earlier suggestion that cimetidine enhances gastric mucosal prostaglandin synthesis. ${ }^{22}$

The present results are different from those obtained by Wright $e t \mathrm{al}^{+}$both in showing enhanced synthesis with gastritis and in failing to find significant differences in patients with gastric ulceration. Trends toward lower levels of endogenous iPGE $_{2}$ and of $\mathrm{iTxB}_{2}$ in gastric ulcer patients do not reach statistical significance and no difference was seen in the comparison of matched pairs of patients. Moreover, there were no local changes in $\mathrm{PGE}_{2}$ or $\mathrm{TxB}_{2}$ synthesis or prostaglandin catabolism in the ulcer rim. Thus in this study gastric ulceration seems at best to be a much weaker influence than suggested by Wright et al who reported reduced levels of $\mathrm{PGE}_{2}$ in patients with gastric ulcers even when the mucosa was inflamed. ${ }^{4}$ There was no evidence of an imbalance between $\mathrm{PGE}_{2}$ and $\mathrm{TxB}_{2}$.

The reasons for the differences betweeen the present data and those of Schlegel et al on the one hand and those reported by Wright et $a l^{4}$ on the other are not clear. The use of homogenates might be insensitive to subtle changes in cyclooxygenase activity and it remains possible that changes in prostanoid synthesis could occur in vivo because of phospholipase activation, the influence of neural stimulation or changes in endogenous synthesis. Specific evidence for such changes in gastric ulcer patients is lacking, however, and these possibilities could not account for the differences between the three studies as all used homogenates. The controls in the present study were 43 patients in whom no 
pathology was found whereas Wright et al used seven normal volunteers. One point that emerged from the use of the patient study number as a quality control measure was that there was a tendency for all parameters measured to rise slightly in value during the course of the study (presumably because of subtle changes in methodology). Because the gastric ulcer patients and their controls were studied concurrently these changes do not influence the comparison between them. Comparable data are not provided in the other studies.

One stimulus for this study was the observation that the incidence of gastric and duodenal ulceration is static or rising in older women in the United Kingdom but falling in other groups..$^{23}{ }^{24}$ Although a balanced group of patients with a wide age distribution was studied there was no evidence that the parameters measured were influenced by age, sex. or smoking. Patients on NSAID's, however, showed reduced prostaglandin synthesis even though they were studied more than 12 hours after their last dose. Comparable differences between patients not on NSAID's and controls were not seen suggesting that reduced prostaglandin dependent processes are less important in this group than in patients taking NSAID's. Wright et al regarded the reduction in synthesis of $\mathrm{PGE}_{2}$ which they observed with gastric ulcer to be a secondary phenomenon. The data reported in the present paper give even fewer grounds for believing that a primary deficiency of prostaglandin synthesis accounts for the development of gastric ulceration in patients not on NSAID's and thus cast some doubt on the clinical relevance of using prostaglandins for mucosal protection of these patients.

This work was supported by a project grant from the Medical Research Council.

\section{References}

I Konturek SJ, Piastucki I, Brzozowski T, et al. Role of locally generated prostaglandins in adaptive gastric cytoprotection. Dig Dis Sci 1982; 27: 967-71.

2 Robert A, Nezamis JE, Lancaster C. Davis JP. Field SO, Hanchar AJ. Mild irritants present gastric necrosis through "adaptive cytoprotection' mediated by prostaglandins. Am J Physiol 1983; 245: G113-G21.

3 Hawkey CJ, Rampton DS. Prostaglandins and the gastrointestinal mucosa; are they important in its function, disease or treatment? Gastroenterology 1985; 89: $1162-88$

4 Wright JP, Young GO, Klaff LJ, Weerss LA, Price SK, Marks IN. Gastric mucosal prostaglandin E levels in patients with gastric ulcer disease and carcinoma. Gastroenterology 1982; 82: 263-7.
5 Konturek SJ. Actions of nonsteroid anti-inflammatory compounds on gastric mucosal integrity and prostaglandin formation in healthy subjects and peptic ulcer patients. Adv Inflammation Res 1984; 6: 29-37.

6 Schlegel W, Wenk K. Dollinger HC, Raptis S. Concentrations of prostaglandin A-. E- and F-like substances in gastric mucosa of normal subjects and of patients with various gastric diseases. Clin Sci Mol Med 1977; 52: $255-8$.

7 Whittle BJR, Kauffman GL, Moncada S. Vasoconstriction with thromboxane $A_{2}$ induces ulceration of the gastric mucosa. Nature 1981; 292: 472-4.

8 Konturek SJ, Brzozowski T, Piastucki I, Radecki T, Dembinska-Kiec A. Role of prostaglandin and thromboxane biosynthesis in gastric necrosis produced by taurocholate and ethanol. Dig Dis Sci 1983; 28: 154-60).

9 Whittle BJR. Cellular mediators in gastric damage: actions of thromboxanc $A_{2}$ and its inhibitors. In: Allen A. Flemstrom G, Garner A. Silen W. Turnberg LA, eds. Mechanisms of mucosal protection in the upper gastrointestinal tract. Raven Press: New York, 1984: 295-3()2.

10) Hawkey CJ, Kemp R. Filipowicz B, Bhaskar NK, Walt $\mathrm{RW}$. Gastric mucosal protection with dazmegrel, an inhibitor of gastric mucosal thromboxane synthesis. Gastroenterology 1985; 88: 1415.

11 Bhaskar NK. Filipowicz B. Hawkey CJ. Inhibition of human gastric mucosal thromboxane synthesis by WHR 2348A. Br J Pharmacol 1985; 85: $268 \mathrm{p}$.

12 Spenney JG. Barton JC. 15 hydroxyprostaglandin dehydrogenase and 13 reductase content of gastrointestinal organs of rabbits and rats. Prostaglandins 1981:21 suppl: 15-24.

13 Peskar BM. Seyberth HW. Peskar BA. Synthesis and metabolism of endogenous prostaglandins by human gastric mucosa. In: Sommelsson B. Ramwell PW. Paoletti R, eds. Advances in prostaglandin and thromboxane research, vol 8. New York: Raven Press, 1980: $1511-4$.

14 Whitehead R. Truelove SC, Gear MW. The histological diagnosis of chronic gastritis in fibreoptic gastroscope biopsy specimens. J Clin Pathol 1972; 25: 1-11.

15 Hawkey CJ. Truelove SC. Inhibition of prostaglandin synthetase in human rectal mucosa. Gut 1983; 24: 213-7.

16 Hawkey CJ, Truelove SC. Effect of prednisolone on prostaglandin synthesis by rectal mucosa in ulcerative colitis: investigation by laminar flow bioassay and radioimmunoassay. Gut 1981; 22: 190-3.

17 Hawkey CJ. Evidence that prednisolone is inhibitory to the cyclo-oxygenase activity of humal colonic mucosa. Prostaglandins 1982; 23: 397-409.

18 Bennett A. Stamford IF, Stockley HL. Estimation and characterization of prostaglandins in the human gastrointestinal tract. Br J Pharmacol 1977; 61: 573-8.

19 Peskar BM. Holland A. Peskar BA. Effect of carbenoxolone on prostaglandin synthesis and degradation. J Pharm Pharmacol 1976; 28: 146-8.

20) Morley J, Bray MA. Jones RW, Nugteren DM, Van Dorp DA. Prostaglandin and thromboxane production by human and guinea pig macrophages and leucocytes. Prostaglandins 1979; 17: 730-6. 
21 Rampton DS, Hawkey CJ. Prostaglandins and ulcerative colitis. Progress report. Gut 1984; 24: 1399-413.

22 Branski D, Sharon P, Karmeli F, Rachmilewitz D. Effect of cimetidine on human gastric and duodenal prostanoid synthesis. Scand J Gastroenterol 1984; 19: 457-60.
23 Coggan D, Lambert P, Langman MJS. 20 years of hospital admissions for peptic ulcer in England and Wales. Lancet 1981; i: 1302-5.

24 Walt RPW, Katschinski B, Logan RFA, Ashley J, Langman MJS. Rising frequency of ulcer perforation in elderly people in the United Kingdom. Lancet 1986; i: 489-92. 